\title{
Perkuatan Struktur Jembatan Kereta Api Rangka Baja Tipe Warren bentang 42 Meter
}

\author{
(Strengthening of Warren Type Steel Railway Bridge Structures 42 meters)
}

\author{
BAgUS SOEBANDONO, BINTANG NOOROHMAD WAHYU NugROHO, ARIQ NAUFAL ANAM, RAKA \\ PUTRA ISMAYANA, TAUFIQ ILHAM MAULANA
}

\begin{abstract}
ABSTRAK
Jembatan kereta api merupakan salah satu prasarana transportasi penting dalam memenuhi kebutuhan manusia. Seiring dengan bertambahnya usia suatu struktur, maka jembatan kereta api juga akan mengalami penurunan kapasitas yang disebabkan oleh faktor internal maupun faktor eksternal. Melihat dari kegunaan jembatan kereta api yang sangat penting, maka dibutuhkan struktur yang kuat serta mampu menjamin keamanan dan keselamatan. Perkuatan merupakan salah satu usaha untuk mengembalikan kapasitas muat suatu struktur sehingga mampu menahan beban yang terjadi. Dalam penelitian ini jembatan kereta api rangka baja tipe warren mengalami penurunan mutu baja sebesar $30 \%$. Analisis dan pemodelan struktur rangka baja menggunakan software SAP2000 V.20 yang kemudian dilakukan perkuatan dengan mengganti elemen-elemen lemah pada struktur rangka baja. Hasil penelitian menunjukan bahwa, nilai mode shapes maksimum setelah dilakukan perkuatan pada arah perpindahan sumbu global X ( UX ) memiliki nilai yang lebih besar $0,072 \%$ dari sebelum dilakukan perkuatan yaitu dari 0,825365 menjadi 0,825962 . Nilai periode (T) juga mengalami peningkatan sebesar $1,603 \%$ dari 0,370023 detik menjadi 0,375957 detik. Lendutan pada tengah bentang jembatan sumbu lokal horizontal searah bidang XY ( U3 ) mengalami penurunan sebesar 32,85\% dari 36,437377 $\mathrm{mm}$ menjadi 24,467447 $\mathrm{mm}$. Pada evaluasi tegangan, terdapat 25 batang yang mengalami field capacity yang kemudian dilakukan perkuatan dengan mengganti 17 batang dengan memperbesar dimensi profil sehingga seluruh batang tidak mengalami field capacity. Nilai tahanan maksimum pada batang yang tidak aman setelah dilakukan perkuatan menjadi lebih kecil dari 25,324 ton menjadi 23,861 ton dengan kapasitas yang meningkat dari 12,612 ton menjadi 34,824 ton.
\end{abstract}

Kata kunci: jembatan kereta api, penurunan mutu, perkuatan rangka baja, periode, lendutan, tegangan

\section{ABSTRACT}

The railway bridge is one of the important transportation infrastructures in meeting human needs. As a structured age, the railway bridge will also experience a decrease in capacity caused by internal and external factors. Seeing from the use of the railway bridges which is very important, it takes a strong structure and can guarantee security and safety. Reinforcement is an effort to restore the load capacity of a structure so that it can withstand the burden that occurs. In this study, the warren type steel frame railroad bridge experienced a $30 \%$ decline in steel quality. Analysis and modeling of steel frame structure using SAP2000 V.20 software which is then performed strengthening by replacing the weak elements in the steel frame structure. The results showed that the value of the maximum mode shapes after the reinforcement in the direction of global X-axis displacement (UX) has a greater value of $0.072 \%$ than before the reinforcement is from 0.825365 to 0.825962 . Period value $(T)$ also increased by $1.603 \%$ from 0.370023 seconds to 0.375957 seconds. Deflection in the middle of the horizontal local axis bridge spread in the direction of the XY (U3) plane decreased by $32.85 \%$ from $36.437377 \mathrm{~mm}$ to $24.467447 \mathrm{~mm}$. In the stress evaluation, there is 25 frames that experience field capacity which is then strengthened by replacing 17 frames by enlarging the profile dimensions so that all the bars do not experience field capacity. The maximum resistance value on the 
unsafe stem after reinforcement is smaller than 25,324 tons to 23,861 tons with capacity increasing from 12,612 tons to 34,824 tons.

Keywords: railway bridges, declining quality, steel frame strengthening, periods, deflection, stress

\section{PENDAHULUAN}

Jembatan merupakan konstruksi bangunan infrastruktur yang berfungsi untuk menghubungkan dan memperlancar lalulintas antara lain menghubungkan jalan yang melewati lembah, jurang, sungai bahkan laut sehingga akses dari satu daerah ke daerah lain menjadi lebih mudah dan cepat. Kereta api menjadi salah satu moda transportasi yang digemari oleh masyarakat karena kapasitas angkut yang banyak, waktu perjalanan relatif cepat dengan tarif yang terjangkau. Sehingga sarana infrastruktur transportasi jembatan kereta api harus selalu dalam kondisi baik. Dalam masa gunanya, Jembatan kereta api rangka baja pengalami penurunan mutu yang mempengaruhi kekuatan struktur dan kualitas layan jembatan tersebut yang diakibatkan faktor internal dan faktor eksternal. Agar jembatan selalu dalam kondisi baik maka harus diperhatikan kelayakan strukturnya. Apabila terjadi penurunan mutu baja dan penyesuaian terhadap peraturan pembebanan kegempaan yang berlaku maka perlu dilakukan kajian analisis berdasarkan perilaku struktur tersebut berdasarkan mode shape, lendutan, dan tegangan.

Menurut Supriyadi dan Muntohar (2007), jembatan pada awalnya hanya sebatang pohon yang ditumbangkan untuk menyebrangi sungai hingga penggunaan beton dan baja dengan berbagai tipe dan metode pelaksanaannya. Jembatan rangka (truss bridge) merupakan jembatan yang didesain untuk bentang yang panjang. Bentang yang dapat menggunakan konstruksi jembatan rangka, yakni lebih dari 180 feet atau $55 \mathrm{~m}$. Tipikal jembatan rangka biasanya terdiri dari elemen-elemen batang yang terletak pada tepi atas dan tepi bawah yang berfungsi sebagai flens pada gelagar yang terhubung dengan elemen batang diagonal dan vertikal yang biasa disebut dengan batang penggantung (hangers) (Rosyidi, 2016). Pada gambar 1 menunjukkan bahwa jembatan rangka tipe warren tersusun dari struktur rangka yang biasa berasal dari material baja yang disusun dengan menyambungkan beberapa batang dengan baut atau las sehingga mempentuk pola segitiga (Satyarno,2003). Struktur jembatan yang memerlukan perkuatan berusaha untuk mengembalikan kapasitas muat jembatan sebagaimana kondisi desain awal jembatan tersebut.

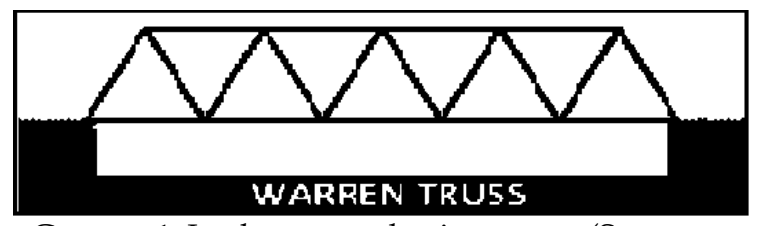

GAMBAR 1. Jembatan rangka tipe warren (Satyarno, 2003)

Analisis mengenai evaluasi dan perbaikan struktur jembatan rangka baja pernah dilakukan oleh Handayani (2013) secara analitis yang kemudian dimodelkan menggunakan SAP 2000. Yudhistira (2014) juga melakukan penelitian untuk memprediksi penurunan kapasitas struktur rangka jembatan dengan metode Artificial Neural Network (AAN) yang menjadi pengembangan dari metode Bridge Management System (BMS).

Banyak metode yang dapat dilakukan untuk perkuatan jembatan rangka baja. Model perkuatan menggunakan prategang eksternal yang dilakukan Rasidi dkk. (2017) dengan penyokong dan tanpa penyokong, Hadi dan Leo (2018) dengan perbedaan bentuk trase kabel prategang yang berbeda-beda, serta Zulkarnain (2013) dengan pemodelan berupa miniatur jembatan rangka baja dengan skala 1:20. Analisis perbandingan metode perkuatan dengan prategang eksternal dengan prategang internal bentuk segitiga pernah dilakukan oleh Budio dkk. (2009). Selain perkuatan menggunakan metode prategang eksternal metode perkuatan lain pernah dilakukan oleh Simatupang dkk. (2016) dengan memperkuat sambungan jembatan menggunakan profil baja ringan C-75 serta Taurus (2013) melakukan perkuatan menggunakan Glass FiberReinforced Polymer (GFRP) pada plat lantai jembatan.

Terjadinya penurunan mutu baja sebesar $30 \%$ dan terbitnya peraturan pembebanan gempa 
SNI 1725:2016 menjadi rumusan masalah untuk dilakukan penelitian perbandingan perilaku struktur rangka atas jembatan kereta api sebelum dan setelah dilakukannya perkuatan dengan metode pergantian batang lemah. Perilaku struktur meliputi mode shape, periode, lendutan dan tegangan yang terjadi pada struktur rangka baja. Tujuan dari penelitian ini untuk menganalisis dan mengkaji perbandingan perilaku struktur rangka atas jembatan sebelum dan setelah dilakukan perkuatan dengan meninjau nilai periode dari mode shape, hasil diplacement dan besar tegangan akibat penurunan mutu baja $30 \%$ dan pembebanan gempa SNI 1725:2016. Penelitian ini diharapkan dapat memberikan pengetahuan dan alternative dalam perkuatan jembatan rangka baja tipe warren setelah mengalami penurunan mutu baja sebesar $30 \%$.

\section{METODE PENELITIAN}

Objek penelitian adalah jembatan kereta api di wilayah operasional Lampung.

Dimensi jembatan meliputi Panjang bentang dan lebar dapat dilihat pada gambar 2 dan gambar 3. Data teknis dari jembatan rangka yang menjadi objek penelitian ini adalah sebagai berikut :
a. Panjang bentang total : $42 \mathrm{~m}$
b. Lebar antar girder $\quad: 1,067 \mathrm{~m}$
c. Lebar jembatan total $: 4,9 \quad \mathrm{~m}$
d. Tinggi rangka jembatan $: 8 \quad \mathrm{~m}$
e. Dimensi rangka batang ( Mutu baja awal - $30 \%$ ) :

- Main frame 400.350.12.12 mm
- Cross girder $1100.400 .16 .28 \mathrm{~mm}$

- Longitudinal girder 700.350.16.28 mm

- Bracing 150.150.7.10 mm

Material yang digunakan pada penelitian ini ialah profil baja (ASTM A36) yang memiliki tegangan leleh sebesar $36 \mathrm{ksi}$ (fy = 2531 $\mathrm{kg} / \mathrm{cm}^{2}$ ) yang diturunkan sebesar $30 \%$ sehingga tegangan lelehnya menjadi $\mathrm{fy}=1771,7 \mathrm{~kg} / \mathrm{cm}^{2}$ dengan modulus elastisitas baja sebesar 2,1 x $10^{6} \mathrm{~kg} / \mathrm{cm}^{2}$. Tahap pemodelan struktur jembatan yang akan dianalisis meliputi :

a. Memodelkan struktur jembatan, material properties dan jenis profil baja dengan program analisis struktur menggunakan software SAP2000 V.20.

b. Melakukan perhitungan pembebanan yang akan di-input pada pemodelan struktur jembatan pada program analasis struktur yang mengacu pada peraturan-peraturan sebagai berikut:

1) Pembebanan untuk jembatan (SNI 1725:2016)

2) PM No. 60 Tahun 2012, Tentang Persyaratan Teknis Jalur Kereta Api

3) PD No. 10 Perencanaan Konstruksi Jalan Rel

4) Perencanaan jembatan terhadap beban gempa (SNI 2833:2016)

5) Peta Gempa 2017

c. Memasukkan beban-beban yang telah diperhitungkan pada model struktur yang telah dibuat. Beban-beban yang di-input antara lain, beban mati,beban hidup, beban kejut, beban lateral kereta api, beban rem dan traksi, beban sentrifugal, beban rel longitudinal, beban angin, beban gempa.

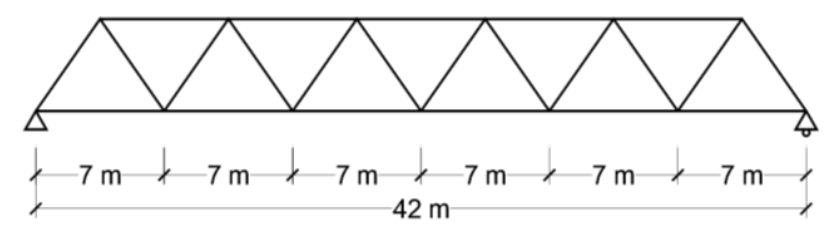

GAMBAR 2. Ukuran panjang bentang

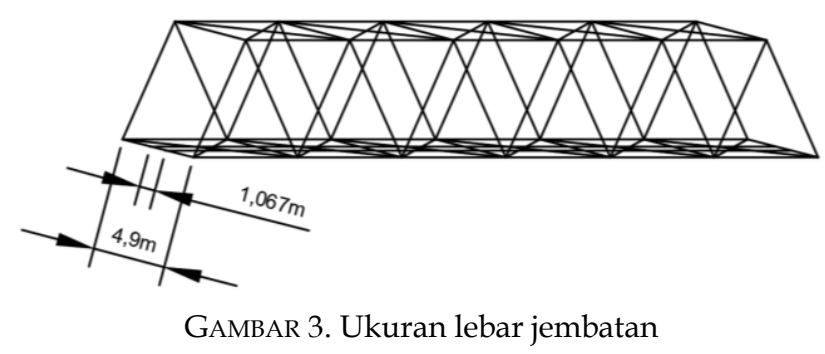


d. Membuat model beban hidup yang berupa muatan gerak dari kereta api dengan menggunakan fasilitas moving load.

e. Menentukan kombinasi pembebanan yang akan di-input pada model struktur jembatan. Kombinasi pembebanan dilakukan untuk menentukan beban maksimum yang bekerja dari semua beban-beban yang telah di-input pada model struktur jembatan.

f. Melakukan "Run Analysis" untuk mendapatkan output/hasil analisis struktur dari pemodelan jembatan yang telah dibuat.

g. Melakukan pergantian batang pada elemen yang over stress dengan memperbesar dimensinya dengan mutu baja A36 (fy = $2531 \mathrm{~kg} / \mathrm{cm}^{2}$ ).

\section{HASIL DAN PEMBAHASAN}

\section{Mode shape}

Nilai mode shape maksimum sebelum perkuatan ditunjukkan pada tabel 1 bahwa pergerakan perpindahan sumbu global X (UX) pada step number mode 6 sebelum perkuatan sebesar 0,82536 satuan perpindahan dengan nilai periode 0,075276 detik dan setelah perkuatan pada tabel 2 nilainya sebesar 0,825962 satuan perpindahan dengan nilai periode 0,073472 detik. Pergerakan perpindahan sumbu global Y (UY) sebelum perkuatan terjadi pada step number mode 1 sebesar 0,432378 satuan perpindahan dengan nilai periode 0,370023 detik dan setelah perkuatan terjadi pada step number mode 2 dengan nilai sebesar 0,442645 satuan perpindahan dengan nilai periode 0,17412 detik. Pergerakan perpindahan sumbu global Z (UZ) terjadi pada step number mode 4 sebelum perkuatan sebesar 0,7308 satuan perpindahan dengan nilai periode 0,124213 detik dan setelah perkuatan sebesar 0,742044 dengan nilai periode 0,124167 detik. Periode getar (T) terbesar yang terjadi pada struktur jembatan sebelum perkuatan sebesar 0,37002 detik dan setelah perkuatan sebesar 0,37595 detik pada mode 1 .

\section{Displacement}

Perbandingan nilai displacement maksimum pada tabel 3 menunjukkan bahwa displacement pada arah sumbu lokal arah X (U1) terjadi di joint 51 pada gambar 4 menunjukkan sebelum perkuatan sebesar $11,222773 \mathrm{~mm}$ dan pada tabel 4 menunjukkan bahwa setelah perkuatan sebesar 6,877212 mm, pada arah sumbu local Y (U2) displacement maksimum terjadi di joint 54 pada gambar 5 menunjukkan sebelum perkuatan sebesar $-0,615116 \mathrm{~mm}$ dan setelah perkuatan sebesar $-0,53632 \mathrm{~mm}$. Pada arah sumbu lokal Z (U3) displacement maksimum terjadi di joint 18 pada gambar 6 menunjukkan sebelum terjadi perkuatan sebesar $-36,437377$ $\mathrm{mm}$ dan setelah perkuatan sebesar $-24,467447$ mm. Tanda min (-) menunjukkan arah displacement berlawanan dengan arah sumbu U2 dan U3.

TABEL 1. Nilai ratio mode shape maksimum sebelum perkuatan

\begin{tabular}{ccccc}
\hline $\begin{array}{c}\text { Mode } \\
\text { No. }\end{array}$ & $\begin{array}{c}\text { Period } \\
\text { (second })\end{array}$ & $\mathrm{UX}$ & $\mathrm{UY}$ & $\mathrm{UZ}$ \\
\hline 6 & 0,0752 & 0,8253 & $6,4 \mathrm{E}-18$ & 0,0650 \\
1 & 0,3700 & 0 & 0,4323 & 0 \\
4 & 0,1242 & 0,0938 & 0 & 0,7308 \\
\hline
\end{tabular}

TABEL 2. Nilai ratio mode shape maksimum setelah perkuatan

\begin{tabular}{ccccc}
\hline $\begin{array}{c}\text { Mode } \\
\text { No. }\end{array}$ & $\begin{array}{c}\text { Period } \\
\text { (second) }\end{array}$ & $\mathrm{UX}$ & $\mathrm{UY}$ & $\mathrm{UZ}$ \\
\hline 6 & 0,0734 & 0,8259 & $1,3 \mathrm{E}-17$ & 0,0470 \\
2 & 0,1741 & 0 & 0,4426 & $2,9 \mathrm{E}-2$ \\
4 & 0,1241 & 0,0706 & $1,1 \mathrm{E}-20$ & 0,7420 \\
\hline
\end{tabular}

TABEL 3. Nilai displacement maksimum sebelum perkuatan

\begin{tabular}{cccc}
\hline Joint & $\begin{array}{c}\mathrm{U} 1 \\
(\mathrm{~mm})\end{array}$ & $\begin{array}{c}\mathrm{U} 2 \\
(\mathrm{~mm})\end{array}$ & $\mathrm{U} 3(\mathrm{~mm})$ \\
\hline 51 & 11,222 & 0,0039 & $-2,5004$ \\
54 & 0,9532 & $-0,6151$ & $-33,340$ \\
18 & 1,4419 & $-0,0260$ & $-36,437$ \\
\hline
\end{tabular}


B. Soebandono, et al./Semesta Teknika, Vol. 22 No. 2, 123-130, November 2019

TABEL 4. Nilai displacement maksimum setelah perkuatan

\begin{tabular}{cccc}
\hline Joint & $\begin{array}{c}\mathrm{U} 1 \\
(\mathrm{~mm})\end{array}$ & $\mathrm{U} 2(\mathrm{~mm})$ & $\mathrm{U} 3(\mathrm{~mm})$ \\
\hline 51 & 6,8772 & $-0,0117$ & $-2,4004$ \\
54 & 0,7464 & $-0,5363$ & $-22,277$ \\
18 & 1,2538 & $-0,0172$ & $-24,467$ \\
\hline
\end{tabular}

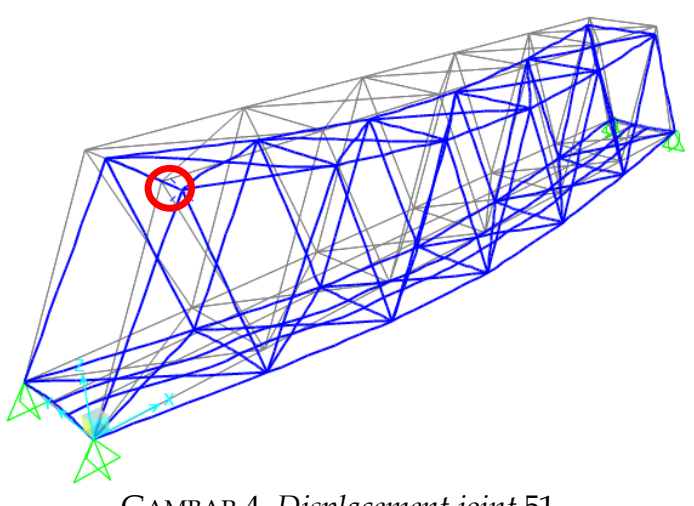

GAMBAR 4. Displacement joint 51

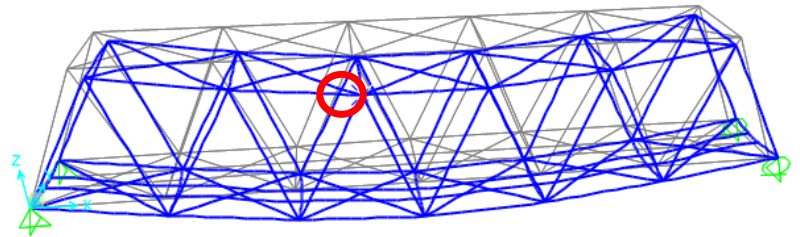

GAMBAR 5. Displacement joint 54

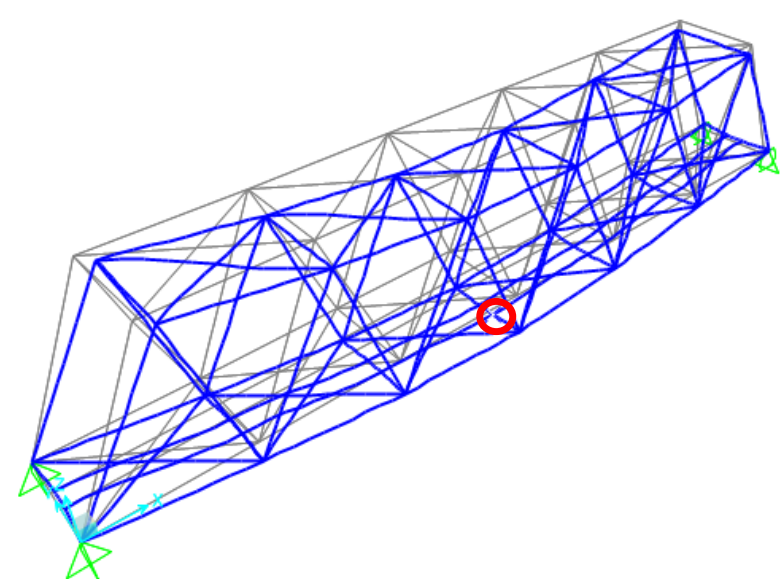

Gambar 6. Displacement joint 18

\section{Besar Tegangan}

Hasil Run Analysis dan check structure pada gambar 7 menunjukan terdapat 25 steel frame yang mengalami failed capacity yaitu pada 2 frame rangka utama, 10 frame ikatan angin atas, 5 frame gelagar melintang dan 8 frame gelagar memanjang. Kemudian dilakukan perkuatan dengan mengganti dimensi profil 10 frame ikatan angin atas (bracing) 150.150.7.10 mm mutu baja - $30 \%$ dengan $150.150 .7 .10 \mathrm{~mm}$ mutu baja $100 \%$ dan 7 frame gelagar melintang (cross girder) $1100.400 .16 .28 \mathrm{~mm}$ menjadi 1100.500.26.28 $\mathrm{mm}$ sehingga seluruh frame menjadi aman ditunujukkan pada gambar 8 .

Lendutan pada struktur ditunjukan oleh displacement maksimum pada arah perpindahan 
sumbu lokal Z (U3), Hasil displacement yang terjadi pada arah perpindahan tersebut sebelum perkuatan memiliki nilai sebesar 36,437377 mm dan setelah perkuatan sebesar 24,467447 $\mathrm{mm}$, lebih kecil dibandingkan dengan nilai lendutan ijin, yaitu sebesar 52,5 mm. Maka, struktur dinyatakan aman terhadap lendutan yang terjadi.
Peningkatan angka keamanan (safety factor) dapat dilihat pada ratio tegangan pada rangka utama (main frame) nomer batang 35 dan 36 pada gambar 9 sebesar 0,956 menjadi 0,719 meningkat $23,7 \%$.

Batang ikatan angin atas (bracing) pada gambar 10 menunjukkan peningkatan ratio menjadi di bawah batas 0.95 .
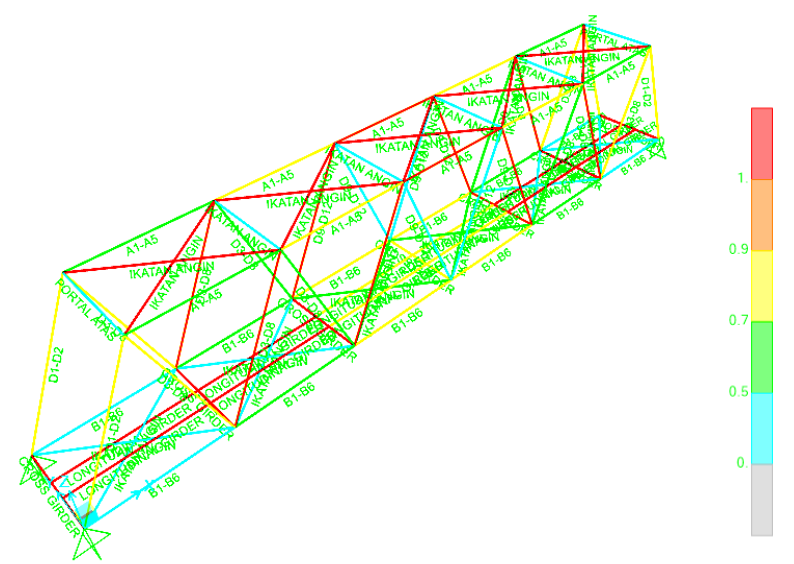

GAMBAR 7. Kondisi sebelum perkuatan

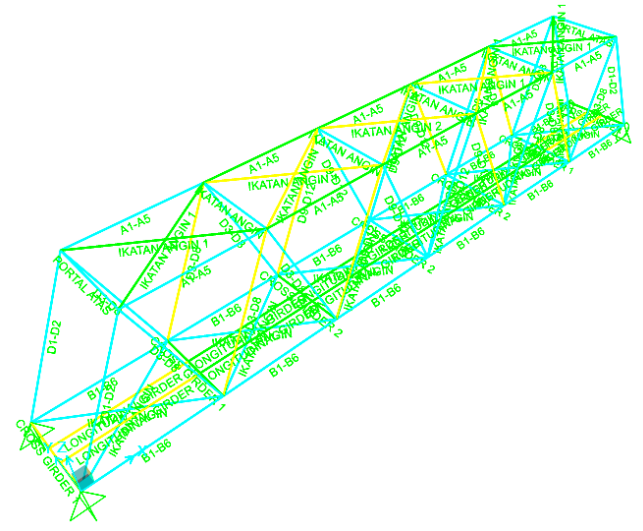

GAMBAR 8. Kondisi setelah perkuatan

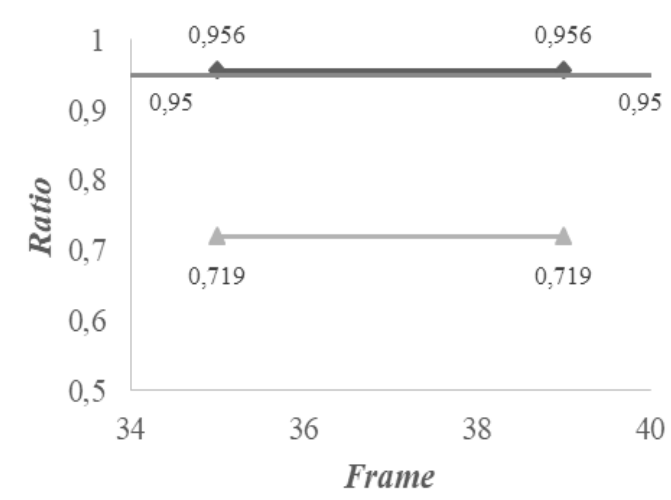

$\multimap$ sebelum perkuatan $\_$setelah perkuatan - limit ratio

GAMBAR 9. Grafik perbandingan nilai ratio frame 35 dan 36 rangka utama

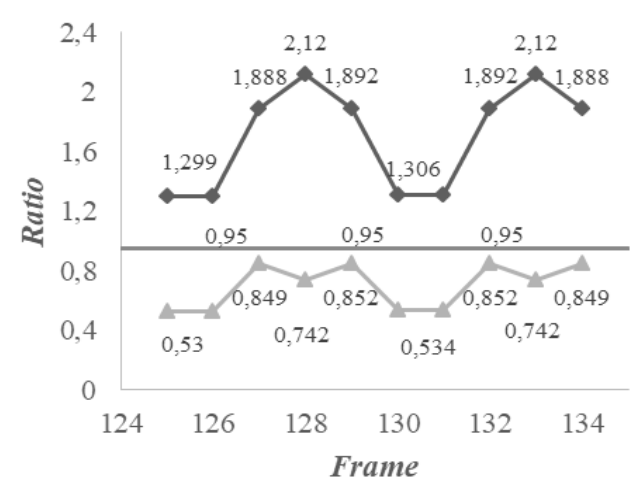

\footnotetext{
$\rightarrow$ sebelum perkuatan $\rightarrow$ setelah perkuatan — limit ratio

GAMBAR 10. Grafik perbandingan nilai ratio pada ikatan angin atas
} 


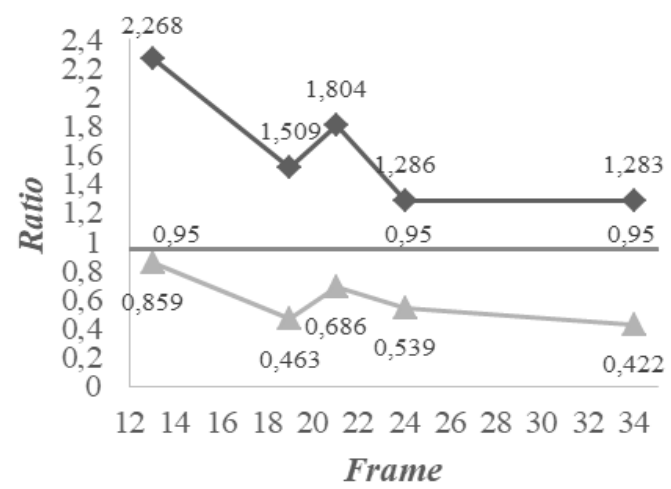

\footnotetext{
$\rightarrow$ sebelum perkuatan $\rightarrow$ setelah perkuatan —limit ratio
}

GAMBAR 11. Grafik perbandingan nilai ratio pada gelagar melintang

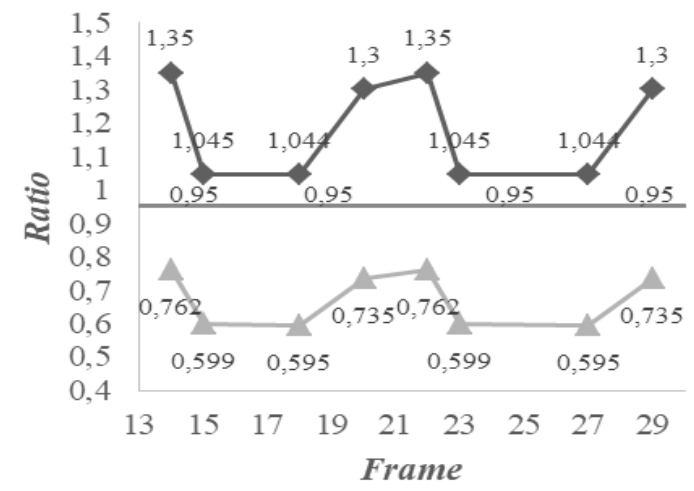

$\leadsto$ sebelum perkuatan $\rightarrow$ setelah perkuatan - limit ratio

GAMBAR 12. Grafik perbandingan nilai ratio pada gelagar memanjang

Peningkatan angka keamanan (safety factor) juga dialami oleh batang gelagar melintang gambar 11 dan gelagar memanjang gambar 12 dibawah batas ratio 0,95 .

\section{KESIMPULAN}

Perkuatan struktur jembatan kereta api rangka baja tipe warren bentang 42 Meter yang telah mengalami penurunan mutu baja $30 \%$ dengan menganalisi ulang dan mengganti batang/frame yang mengalami over stress menghasilkan peningkatan nilai periode, memperkecil nilai lendutan dan memperkecil nilai ratio tegangan sehingga menghasilkan konstruksi yang kembali aman.

\section{DAFTAR PUSTAKA}

Budio, Sugeng P., Wibowo, Ari dan Antara, I Komang., (2009), Prosentase Penurunan Lendutan Model Jembatan Rangka Baja Akibat Penggunaan Kabel Prategang
Internal Tipe Segitiga. Rekayasa Sipil, 3(1), 37-49.

Hadi, Nicolas dan Leo, Edison.,(2018), Analisis Perbandingan Jembatan rangka Baja engan Metode Prategang Eksternal Ditinjau dari Bentuk Trase Kabel Prategang. Jurnal Mitra Teknik, 1(1), 230-239.

Handayani, Tri., (2013), Evaluasi Penyebab Kegagalan dan Perbaikan Struktur jembatan Rangka Baja dengan Bentang 53 Meter. M. I. Mat. Konst., 13, 17-25.

Rasidi, Nawir, Ningrum, Diana dan S.W, Lalu Gusman., (2017), Analisis Alternatif Perkuatan Jembatan Rangka Baja (Studi Kasus : Jembatan Rangka Baja SoekarnoHatta Malang). Program Studi Teknik Sipil Universitas Tribhuwana Tunggadewi, Malang.

Rosyidi, Sri Atmaja P., (2016), Rekayasa Jalan Kereta Api. Yogyakarta: LP3M Universitas Muhammadiyah Yogyakarta. 
Simatupang, Martin Rolan, Laksono, Susanti, Lilya dan Perkasa, Erlangga Adang., 2016, Studi Analisis dan Eksperimental Pengaruh Perkuatan Sambungan pada Struktur Jembatan Rangka Canai Dingin Terhadap Lendutannya. Rekayasa sipil, 10(3), 205-210.

Satyarno, Imam., (2003), Analisis Struktur Jembatan. Yogyakarta: Jurusan Teknik Sipil Universitas Gadjah Mada.

Supriyadi, Bambang., Muntohar, Agus Setyo., (2007), Jembatan. Cetakan ke-5. Yogyakarta: Beta Offset.

Taurus, Fery., (2013)., Kinerja Jembatan Ranka Baja Yang Diperkuat Dengan GFRP (Glass Fiber-Reinforced Polymer). Jurnal Rekayasa, 17(2), 123-132.

Yudhistira, Angga Trisna., (2014), Perdiksi Penurunan Kapasitas Struktur Atas Jembatan Rangka Baja Dengan Metode Artificial Neural Network: Tesis Minat Studi Teknik Struktur Program S2 Teknik Sipil, Tesis, Universitas Gadjah Mada, Yogyakarta.

Zulkarnain, Alexander., (2013), Pemodelan Jembatan Rangka Baja Dengan Perkuatan Pratekan Eksternal. Jurusan Teknik Sipil Mercu Buana, Jakarta.

PENULIS:

\section{Bagus Soebandono}

Prodi Teknik Sipil, Fakultas Teknik, Universitas Muhammadiyah Yogyakarta, Jl. Brawijaya, Tamantirto, Kasihan, Bantul, Yogyakarta.

Email: bagus_soebandono@umy.ac.id

Bintang Noorohmad Wahyu Nugroho

Prodi Teknik Sipil, Fakultas Teknik, Universitas Muhammadiyah Yogyakarta, Jl. Brawijaya, Tamantirto, Kasihan, Bantul, Yogyakarta.

Ariq Naufal Anam

Prodi Teknik Sipil, Fakultas Teknik, Universitas Muhammadiyah Yogyakarta, Jl. Brawijaya, Tamantirto, Kasihan, Bantul, Yogyakarta.
Raka Putra Ismayana

Prodi Teknik Sipil, Fakultas Teknik, Universitas Muhammadiyah Yogyakarta, Jl. Brawijaya, Tamantirto, Kasihan, Bantul, Yogyakarta

Taufiq Ilham Maulana

Prodi Teknik Sipil, Fakultas Teknik, Universitas Muhammadiyah Yogyakarta, Jl. Brawijaya, Tamantirto, Kasihan, Bantul, Yogyakarta. 